\title{
Sensitive Films for Optical Detection of Ammonia and Nitrogen Dioxide
}

\author{
C. Tyszkiewicz*, P. Karasiński And R. Rogoziński \\ Department of Optoelectronics, Silesian University of Technology \\ Akademicka 2, 44-100 Gliwice, Poland
}

\begin{abstract}
The sol-gel technology allows preparation of the thin silica films ranging in porosity from dense to highly porous. These films can function as matrix binding molecules of $\mathrm{pH}$-sensitive indicators and can be utilized as sensitive coatings for intensity based planar evanescent wave chemical sensors. This paper is devoted to manufacturing technology and characterization of highly porous silica films deposited on soda-lime glass substrates, impregnated with bromocresole purple and cresole red. Two different methods of impregnation were used: dip coating, which entails sensitization of both silica films deposited on each side of a substrate and selective deposition of a dye solution on single side of the substrate. Manufactured sensitive films were tested toward influence of gaseous ammonia and nitrogen dioxide on their spectral characteristics of the absorption coefficient and the imaginary part of the refractive index. It was shown that bromocresole purple allows detection of both gases: $\mathrm{NH}_{3}$ and $\mathrm{NO}_{2}$.
\end{abstract}

PACS: 81.20.Fw, 42.70.Ce, 07.07.Df

\section{Introduction}

Ammonia and nitrogen dioxide are gases that naturally occur in the atmosphere as well as are human activities product. Therefore qualitative and quantitative methods for detection of these gases are required. These gases are harmful for human health $[1,2]$ and are environmental pollutants. An average person detects $\mathrm{NH}_{3}$ by odor at $17 \mathrm{ppm}$ and $\mathrm{NO}_{2}$ at $1.1 \mathrm{ppm}$. According to the WHO maximal admissible concentration of $\mathrm{NH}_{3}$ allowed for people over $8 \mathrm{~h}$ is $25 \mathrm{ppm}$ and over $10 \mathrm{~min}$ $35 \mathrm{ppm}$. Hourly limit value of $\mathrm{NO}_{2}$ concentration for the protection of human health is $0.08 \mathrm{ppm}$. The measurement of $\mathrm{NH}_{3}$ and $\mathrm{NO}_{2}$ concentration in air and water is important in agricultural industry, chemical industry, and medical diagnosis in wide range of concentrations. Because an instrumental analysis is expensive and time-consuming new methods for determination of $\mathrm{NH}_{3}$ and $\mathrm{NO}_{2}$ concentration are being developed. Chemiresistive sensors based on semiconducting metal oxides usually operate in the concentration range $1 \mathrm{ppb}-100 \mathrm{ppm}$ and for operation require high temperature $\left(200-400^{\circ} \mathrm{C}\right)$ which limits their application field [3]. Optical sensors based on organic sensing films are often able to operate at room temperature. The sensing mechanisms utilized in optical gas sensors rely on changes of sensing film absorbance spectrum or on luminescence phenomena. It was shown in the paper [4] that rhodamine $\mathrm{B}$ hydrazide molecules upon chemical reaction with $\mathrm{NO}_{2}$ turn purple and simultaneously a luminescence peak at $\approx 580 \mathrm{~nm}$ is observed. In the paper [5] there is shown $\mathrm{NH}_{3}$ sensor exploiting the phenomenon of upconversion luminescence based on the

* corresponding author; e-mail: cuma.tyszkiewicz@polsl.pl use of upconverting nanoparticles of the $\mathrm{NaYF}_{4}: \mathrm{Yb}, \mathrm{Er}$ type that can be excited with $980 \mathrm{~nm}$ laser light to give a green and red luminescence. Utilization of guest binding effect can enhance sensor sensitivity and reduce its cross-sensitivity. In the paper [6] there was shown how to functionalize calixarene molecules to give guest binding effect with gaseous $\mathrm{NO}_{2}$ - alkylated calixarenes form nitrosonium complexes that change their color. Among the materials that change their absorption spectrum upon interaction with gases are $\mathrm{pH}$-indicators. In the paper [7] there was shown the reflective ammonia sensor utilizing pH-dyes immobilized in porous silica films produced by means of thermal oxidation of etched silicon wafers and in chitosan/GPTMS films (GPTMS - glycidoxypropyltrimethoxysilane). In our research group dyes are immobilized in porous silica films fabricated by means of sol-gel method $[8,9]$. Such films of low porosity $(P \approx 7 \%)$, doped with bromocresole purple (BP) and high porosity $(P \approx 50 \%)$ doped with $\mathrm{BP}$ and bromothymole blue (BB) were earlier investigated in our research group and applied in planar amplitude ammonia sensor [10-12].

Absorption changes of sensitive films can be detected by planar sensor structures utilizing evanescent wave spectroscopy (planar evanescent wave sensors, PEWS). In such structures a propagating optical wave penetrates a sensitive film with its evanescent wave [13-15]. Therefore changes in sensitive film absorption cause changes in amplitude of propagating waveguide modes (light intensity changes). Optical sensors can be fabricated using optical fibres [16, 17] or planar waveguides [12, 18]. An application of the planar or channel waveguides allows for an optimization of optical and geometrical parameters of an optical transducer in wide range [19-24].

This paper is devoted to fabrication and characterization of sensing films for optical sensing of ammonia and 
nitrogen dioxide. Discussed films are made of a porous silica which constitutes a matrix bonding $\mathrm{pH}$ sensitive indicators (dyes): BP and cresole red (CR). The sensing mechanism is described in Sect. 2. Porous silica films fabrication technology and two methods of films sensitization are described in Sect. 3. Characterization methods are described in Sect. 4. The influence of $\mathrm{NH}_{3}$ and $\mathrm{NO}_{2}$ on spectral characteristics of absorbance and imaginary part of refractive index are presented in Sect. 5 .

\section{Sensing mechanism}

Fig. 1 illustrates a sensing mechanism which leads to spectral shift of an indicator absorption band whose spectral position is determined by indicator protonation. A ratio of protonated and deprotonated form of the indicator determines the dominant absorption band and is dependent on the indicator's pKa value. According to Le Chatelier's rule a presence of gaseous $\mathrm{NH}_{3}$ or $\mathrm{NO}_{2}$ shifts the dynamic equilibrium which determines the aforementioned ratio. This leads to a change of the dominant absorption band.

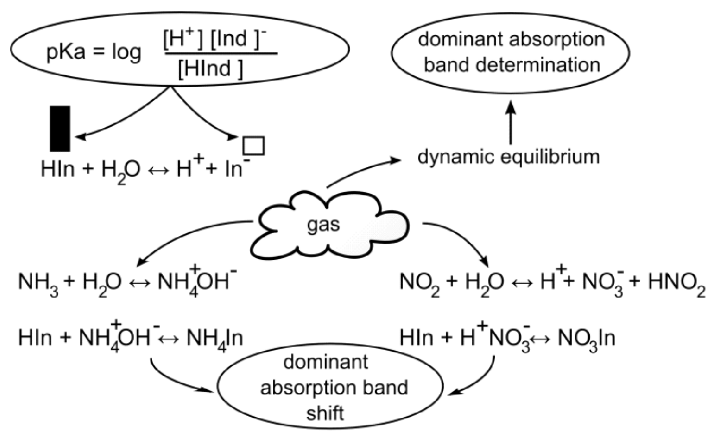

Fig. 1. Sensing mechanism leading to changes in sensitive film absorption. Ind $-\mathrm{pH}$ sensitive indicator.

\section{Technology}

The sol-gel method allows fabrication of glasses and ceramics from a liquid phase. The fabrication process can be split into the following subsequent stages: formation of the colloidal system, hydrolysis and condensation, deposition of a sol layer on the substrate, drying and annealing of the fabricated film [8]. The tetraethyl orthosilicate $\mathrm{Si}\left(\mathrm{OC}_{2} \mathrm{H}_{5}\right)_{4}$ was used as a silica precursor in all technological processes that led to fabrication of the sensing films described in this paper. Ethanol was used as a solvent and hydrochloric acid as a catalyst. The molar ratio of initial components and the amount of catalyst as well as parameters characterizing course of each stage in sol-gel process have the influence on parameters of the fabricated film. The prime advantage of the sol-gel method is a capability of controlling the structure of fabricated material. The other advantages are: high uniformity of fabricated films, low temperature of the fabrication process and capability of different material formation (films, fibres, powders). The sensing properties of fabricated films are governed by their porosity and $\mathrm{pH}$-indicator type. The values of porosity have an influence on sensing films responsiveness and regeneration time. High porosity of fabricated sensing films was achieved by admixture to a sol of a nonpolar surface agent Triton X-100. The agent reduces a surface tension between a solution and a substrate and the internal tension occurring on the condensation stage leads to a contraction and a densification of a material structure.

Silica films were deposited on glass substrates using the dip-coating method which entails that there are two films one on each side of a substrate. A thickness of fabricated films was controlled through the withdrawal speed of substrates from a sol. Sol films deposited on substrates were dried and annealed for $40 \mathrm{~min}$ at $425^{\circ} \mathrm{C}$. The fabricated porous films were impregnated with a bromocresole purple and a cresole red. The $\mathrm{pH}$ sensitive indicators were dissolved in EtOH. Each solution contained $0.001 \mathrm{~mol}$ of an indicator per $100 \mathrm{~mL}$ of EtOH. Two methods of impregnation were utilized. In the first method, from here referred to as "dip coating", a substrate was immersed in a $\mathrm{pH}$-indicator solution and then after 10 min withdrawn with controlled speed. This method has an advantage of excellent controlling over uniformity of deposition. However it has as well a major drawback. Namely both films are impregnated throughout their whole surface. In the second method, from here referred to as "selective coating", only one porous silica film was covered with $\mathrm{pH}$ indicator solution using a fine brush. Dip coated sensing films were dried for $15 \mathrm{~min}$ at $90^{\circ} \mathrm{C}$.

\section{Measuring methods}

Investigations on a fabrication of sensitive films were broken down into three stages. In the first, stage involving fabrication technology of porous silica films deposited on glass substrates, a thickness and refractive index of films were measured with a monochromatic ellipsometer Sentech SE400 $(\lambda=632.8 \mathrm{~nm})$. In the second stage spectral transmission characteristics $T(\lambda)$ of porous silica films before and after impregnation were registered. In the third stage spectral transmission characteristics of sensitive films subjected to a gas (gas exposure sequence) and after that to dry air were registered (purge sequence). For transmission characteristics naming, the following convention is adopted: $T_{x}(\lambda), x=\mathrm{i}, \mathrm{z}, \mathrm{o}$, where i — impregnated film, $\mathrm{z}$ - impregnated film exposed to a gas, o - impregnated film exposed to dry air after exposition to a gas.

All $T(\lambda)$ characteristics were registered using Ocean Optics HR4000CG UV-VIS spectrophotometer. A lamp Mikropack DT-MINI-2-GS was used as wideband light source. The range of wavelengths over which spectra were registered is $190-1100 \mathrm{~nm}$ with resolution $0.75 \mathrm{~nm}$ but their presentation is limited to the range $450-650 \mathrm{~nm}$. The schematic diagram of the measurement setup is presented in Fig. 2. Nitrogen dioxide was dosed into the gas chamber from the bottle containing dry synthetic air-based mixture of concentration 2000 ppm. Measured 
relative humidity of synthetic air was $\mathrm{RH}=7 \%$ at a temperature of $22^{\circ} \mathrm{C}$. Ammonia was dosed from the ammonia water.

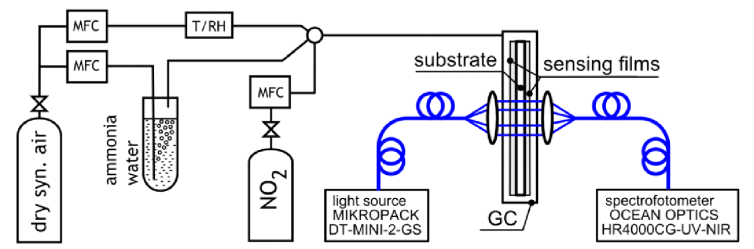

Fig. 2. Experimental setup for determination of the spectral transmission characteristics. MFC - mass flow controller, $\mathrm{T} / \mathrm{RH}$ - temperature and relative humidity sensor, GC - gas chamber.

Taking an assumption that a porous silica film of a thickness $d$ is uniformly impregnated with given $\mathrm{pH}$ -indicator, spectral transmission characteristics of an increase of attenuation coefficient $\Delta \alpha(\lambda)$ and of a refractive index imaginary part $\Delta \kappa(\lambda)$ can be calculated using the following equations:

$$
\begin{aligned}
& \Delta \alpha_{i-y=z, \mathrm{o}}(\lambda)=\frac{\ln 10}{d} \log \frac{T_{\mathrm{i}}(\lambda)}{T_{y=\mathrm{z}, \mathrm{o}}(\lambda)}, \\
& \Delta \kappa_{i-y=\mathrm{z}, \mathrm{o}}(\lambda)=\frac{\lambda \ln 10}{4 \pi d} \log \frac{T_{\mathrm{i}}(\lambda)}{T_{y=\mathrm{z}, \mathrm{o}}(\lambda)},
\end{aligned}
$$

where $\lambda$ is a wavelength, $d$ is a thickness of a sensitive film, $T_{\mathrm{i}}(\lambda), T_{\mathrm{z}}(\lambda), T_{\mathrm{o}}(\lambda)$ are spectral transmission characteristics registered before exposition to a gas (i), after exposition to the gas $(\mathrm{z})$ and following after exposition to dry air (o).

\section{Experimental results}

A main parameter of the dip-coating method which allows control over film thickness is a withdrawal speed of the substrate from sol. Technological characteristics presenting dependences of a sensitive film thickness $d$ and a refractive index $n$ in function of withdrawal speed $v$ are presented in Fig. 3. The relationship $n(v)$ can be approximated by Eq. (3):

$$
n=1.2387(20)-0.0013(4) \xi \nu,
$$

where $\xi=1 \mathrm{~s} / \mathrm{cm}$.

For substrate withdrawal speed in range $v=3.06-$ $7.27 \mathrm{~cm} / \mathrm{min}$ fabricated films thickness are in range $d=$ $537-906 \mathrm{~nm}$. The increase in withdrawal speed results in decrease of a film refractive index. Such a relationship is typical for polymeric sols in case of weakly charged polymers and high condensation speed [8].

Low refractive index is a consequence of a silica film high porosity. The porosity can be estimated using the approximated equation describing effective refractive index of the medium: $n=n_{\text {air }} P+n_{\mathrm{d}}(1-P)$, where $n_{\text {air }}=1$ is a refractive index of air and $n_{\mathrm{d}}=1.4585$ is refractive index of solid silica at wavelength $\lambda=632.8 \mathrm{~nm}$. The porosity $P$ of fabricated films is approximately 0.5 .

Films doped with $\mathrm{CR}$ were sensitive to $\mathrm{NO}_{2}$ but not to $\mathrm{NH}_{3}$. In Fig. 4 there are presented transmission characteristics of CR-doped, dip coated sensitive film. The

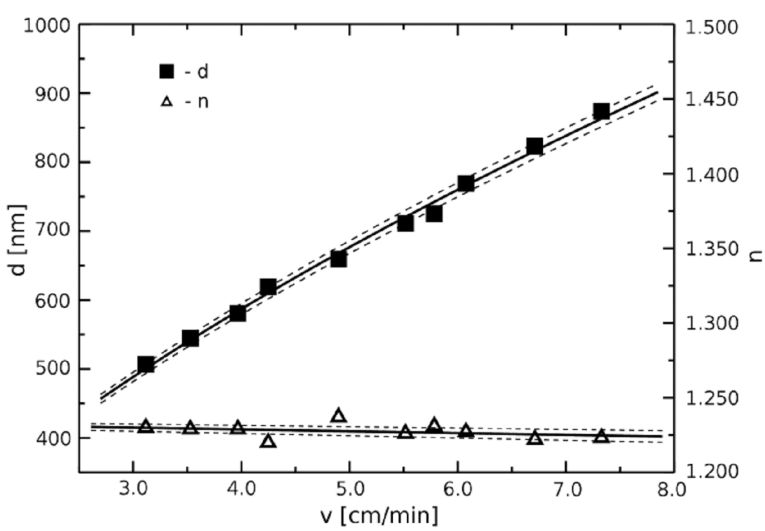

Fig. 3. Technological characteristics of a porous silica film thickness $d$ and refractive index $n$ in function of the withdrawal speed $v$ of a substrate from a sol $(\lambda=$ $632.8 \mathrm{~nm})$.

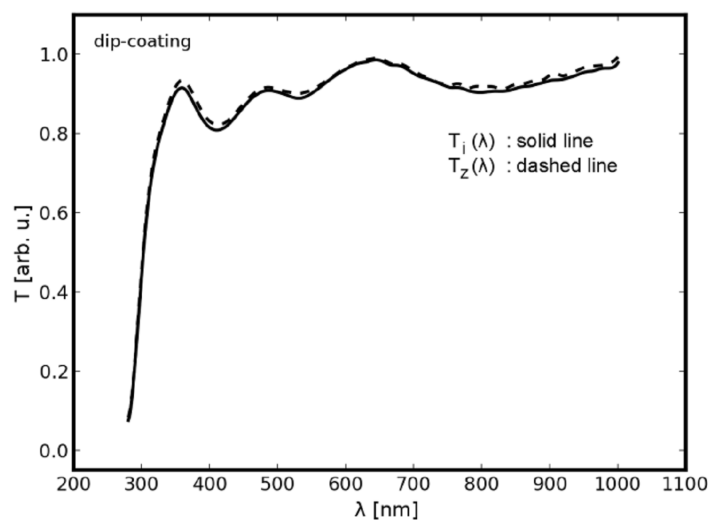

Fig. 4. Spectral transmission characteristics of the CR-doped, dip coated sensitive film. $T_{\mathrm{i}}(\lambda)$ is a spectrum registered after impregnation, $T_{\mathrm{z}}(\lambda)$ is a spectrum registered after exposition to $\mathrm{NH}_{3}$.

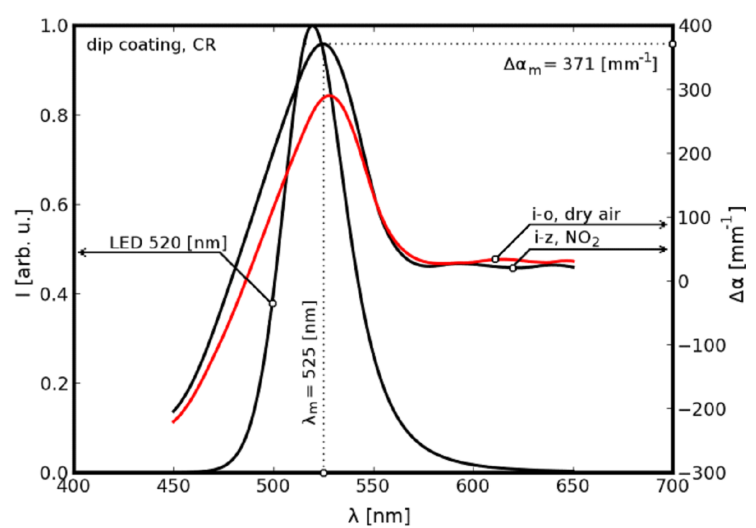

Fig. 5. Spectral characteristics of attenuation coefficient increase $\Delta \alpha(\lambda)$ for CR-based sensitive film and normalized spectral emission characteristic $I(\lambda)$ of LED matching the $\mathrm{NO}_{2}$ induced absorbance band. Sensitization by means of dip coating process. Exposure to $\mathrm{NO}_{2}$. 


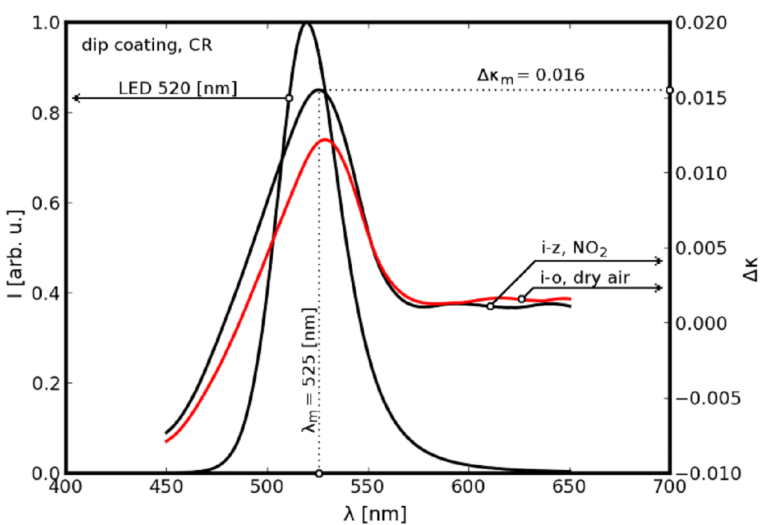

Fig. 6. Spectral characteristics of a imaginary part of refractive index increase $\Delta \kappa(\lambda)$ for CR-based sensitive film and normalized spectral emission characteristic $I(\lambda)$ of LED matching the $\mathrm{NO}_{2}$ induced absorbance band. Sensitization by means of dip coating process. Exposure to $\mathrm{NO}_{2}$.

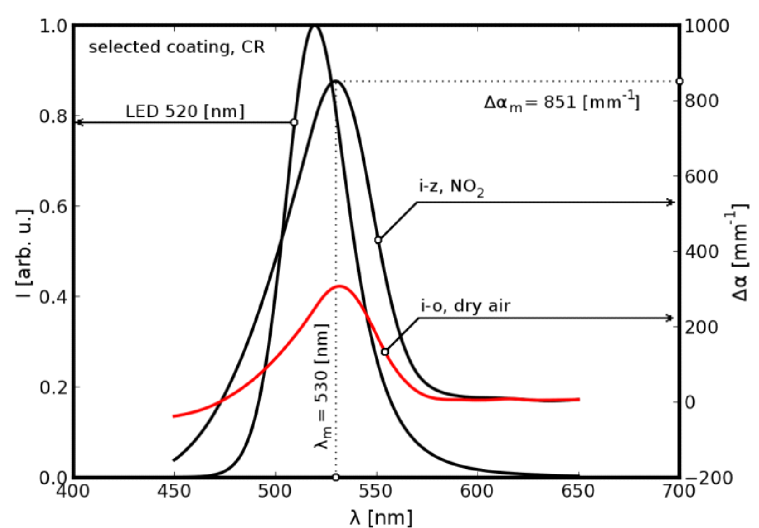

Fig. 7. Spectral characteristics of attenuation coefficient increase $\Delta \alpha(\lambda)$ for CR-based sensitive film and normalized spectral emission characteristic $I(\lambda)$ of LED matching the $\mathrm{NO}_{2}$ induced absorbance band. Sensitization by means of selective coating process. Exposure to $\mathrm{NO}_{2}$.

$T_{\mathrm{z}}(\lambda)$ characteristic was registered after exposition to ammonia. The $T_{\mathrm{i}}(\lambda)$ and $T_{\mathrm{z}}(\lambda)$ are slightly shifted but an absorbance band is not formed after exposition.

In five pairs of figures presented below there are shown spectral characteristics of attenuation coefficient increase and imaginary part of refractive index increase for CR and BP-sensitized films. In each figure the following characteristics are presented: $(\mathrm{i}-\mathrm{z})$ registered during a gas-exposure sequence after $40 \mathrm{~s}$ from its start, ( $\mathrm{i}-\mathrm{O})$ registered during purge sequence after $400 \mathrm{~s}$ from its start, normalized spectral characteristics of LED diodes whose spectral emission characteristics match absorbance bands induced by a presence of gases. All experiments were carried out at a temperature of $22^{\circ} \mathrm{C}$. The maximal values of $\Delta \alpha$ and $\Delta \kappa$ as well as wavelengths for which they oc-

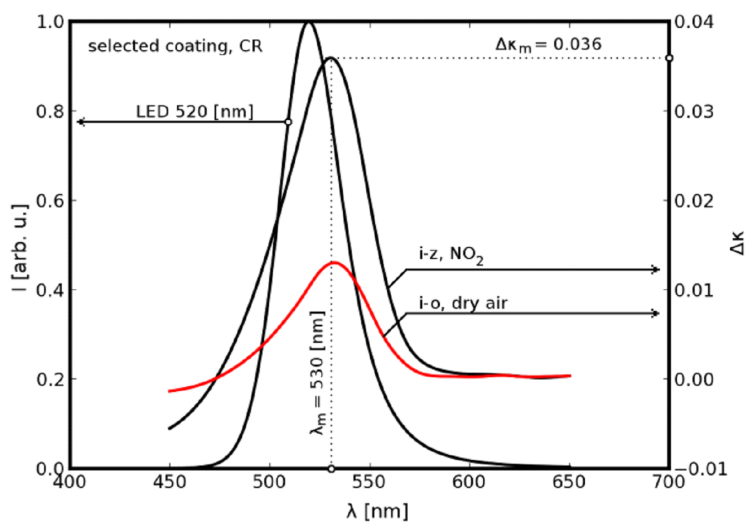

Fig. 8. Spectral characteristics of a imaginary part of refractive index increase $\Delta \kappa(\lambda)$ for CR-based sensitive film and normalized spectral emission characteristic $I(\lambda)$ of LED matching the $\mathrm{NO}_{2}$ induced absorbance band. Sensitization by means of selective process. Exposure to $\mathrm{NO}_{2}$.

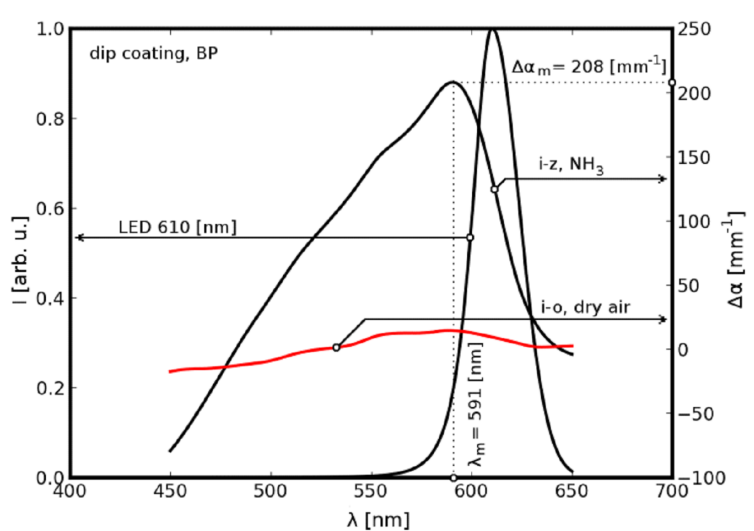

Fig. 9. Spectral characteristics of attenuation coefficient increase $\Delta \alpha(\lambda)$ for BP-based sensitive film and normalized spectral emission characteristic $I(\lambda)$ of LED matching the $\mathrm{NH}_{3}$ induced absorbance band. Exposure to $\mathrm{NH}_{3}$.

curred were extracted from $\Delta \alpha_{\mathrm{i}-\mathrm{z}}(\lambda)$ and $\Delta \kappa_{\mathrm{i}-\mathrm{z}}(\lambda)$ characteristics.

Two first pairs of characteristics are obtained for CR-doped sensitive films subjected to $\mathrm{NO}_{2}$. Characteristics presented in Fig. 5 and Fig. 6 are obtained for films sensitized using dip coating method, whereas those presented in Fig. 7 and Fig. 8 by means of a selective coating method.

Characteristics presented in Figs. 9-14 are obtained for BP sensitized films. The comparison between sensitization methods is presented for exposition to $\mathrm{NH}_{3}$. In Figs. 13 and 14 there are presented characteristics for exposition to $\mathrm{NO}_{2}$. In Figs. 9-14 sensitization is by means of dip coating process. 


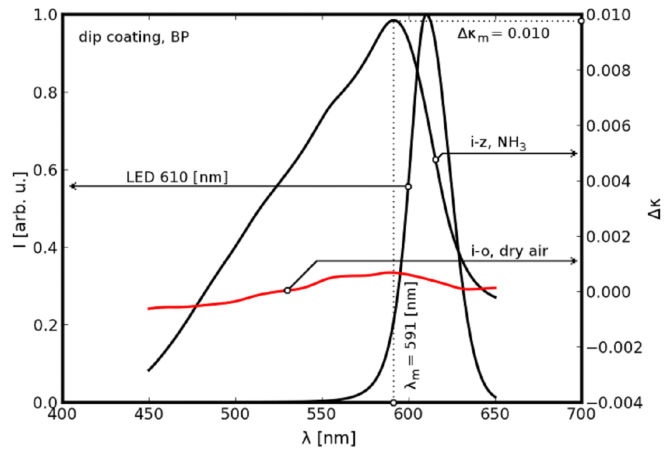

Fig. 10. Spectral characteristics of a imaginary part of refractive index increase $\Delta \kappa(\lambda)$ for BP-based sensitive film and normalized spectral emission characteristic $I(\lambda)$ of LED matching the $\mathrm{NH}_{3}$ induced absorbance band. Exposure to $\mathrm{NH}_{3}$.

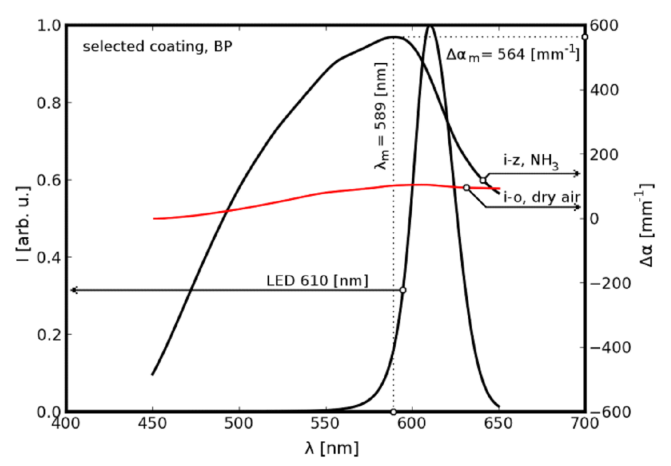

Fig. 11. Spectral characteristics of attenuation coefficient increase $\Delta \alpha(\lambda)$ for BP-based sensitive film and normalized spectral emission characteristic $I(\lambda)$ of LED matching the $\mathrm{NH}_{3}$ induced absorbance band. Exposure to $\mathrm{NH}_{3}$.

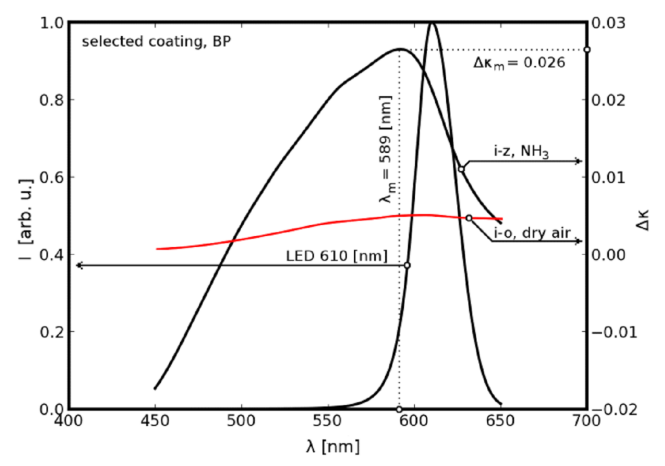

Fig. 12. Spectral characteristics of a imaginary part of refractive index increase $\Delta \kappa(\lambda)$ for BP-based sensitive film and normalized spectral emission characteristic $I(\lambda)$ of LED matching the $\mathrm{NH}_{3}$ induced absorbance band. Exposure to $\mathrm{NH}_{3}$.

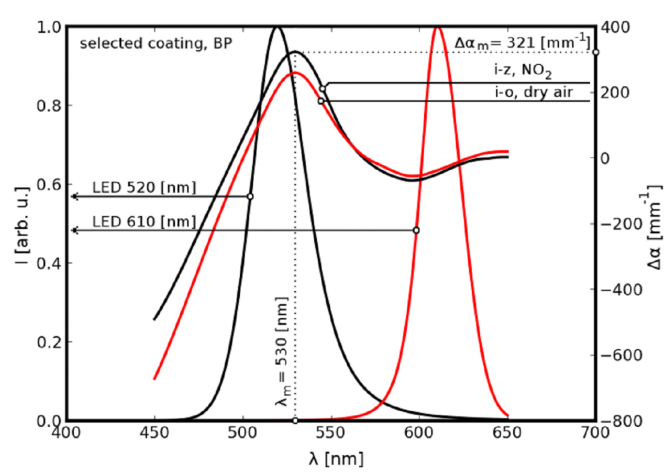

Fig. 13. Spectral characteristics of attenuation coefficient increase $\Delta \alpha(\lambda)$ for BP-based sensitive film and normalized spectral emission characteristic $I(\lambda)$ of both LEDs matching the $\mathrm{NH}_{3}$ and $\mathrm{NO}_{2}$ induced absorbance. Exposure to $\mathrm{NO}_{2}$.

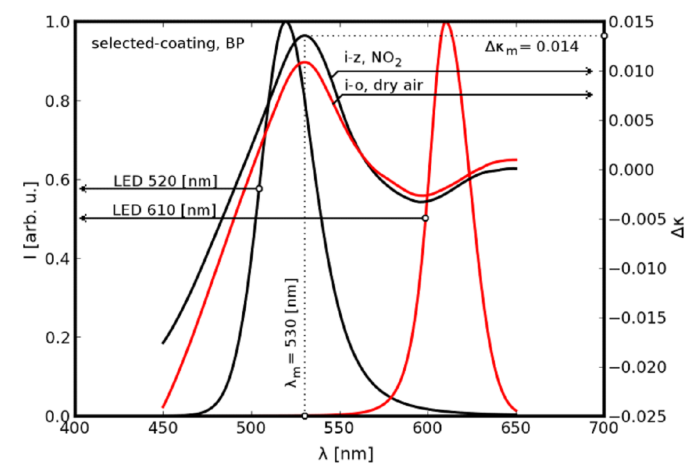

Fig. 14. Spectral characteristics of a imaginary part of refractive index part increase $\Delta \kappa(\lambda)$ for BP-based sensitive film and normalized spectral emission characteristic $I(\lambda)$ of both LEDs matching the $\mathrm{NH}_{3}$ and $\mathrm{NO}_{2}$ induced absorbance. Exposure to $\mathrm{NO}_{2}$.

\section{Discussion}

The comparison of maximal values of $\Delta \alpha_{\mathrm{m}}$ and $\Delta \kappa_{\mathrm{m}}$ show substantial increase of both these parameters for films sensitized by means of selective coating. Values of $\Delta \alpha_{\mathrm{m}}$ for CR-based and BP-based sensitive films are presented in Table I and Table II. The aforementioned increase of $\Delta \alpha_{\mathrm{m}}$ and $\Delta \kappa_{\mathrm{m}}$ is caused by formation of an additional dye film on the top of a porous silica film.

It can be seen that BP is sensitive to both gases: ammonia and nitrogen dioxide. Absorbance bands induced by these gases are separated enough that their detection can be performed by two LED diodes operating at central wavelengths $519 \mathrm{~nm}$ and $611 \mathrm{~nm}$. A wavelength $\lambda_{\mathrm{m}}$ for which maximal absorbance occurs is slightly dependent on sensitization method. The averaged $\lambda_{\mathrm{m}}$ of ammonia induced band in BP-based films is $590 \mathrm{~nm}$ whereas for nitrogen dioxide in CR-based films is $527.5 \mathrm{~nm}$. Comparing the $\mathrm{i}-\mathrm{z}$ and $\mathrm{i}-\mathrm{O}$ characteristics it can be seen that 


\section{TABLE I}

Maximal values of attenuation increase $\Delta \alpha_{\mathrm{m}}$ and imaginary part of refractive index increase $\Delta \kappa_{\mathrm{m}}$ for CR-based sensitive films. Exposure to $\mathrm{NO}_{2}$.

\begin{tabular}{c|c|c}
\hline \hline $\begin{array}{c}\text { Sensitization } \\
\text { method }\end{array}$ & $\Delta \alpha_{\mathrm{m}}\left[\mathrm{mm}^{-1}\right]$ & $\Delta \kappa_{\mathrm{m}}$ \\
\hline dip coating & 371 & 0.016 \\
selective coating & 851 & 0.036
\end{tabular}

\section{TABLE II}

Maximal values of attenuation increase $\Delta \alpha_{\mathrm{m}}$ and imaginary part of refractive index increase $\Delta \kappa_{\mathrm{m}}$ for BP-based sensitive films. Exposure to $\mathrm{NH}_{3}$.

\begin{tabular}{c|c|c}
\hline \hline $\begin{array}{c}\text { Sensitization } \\
\text { method }\end{array}$ & $\Delta \alpha_{\mathrm{m}}\left[\mathrm{mm}^{-1}\right]$ & $\Delta \kappa_{\mathrm{m}}$ \\
\hline dip coating & 208 & 0.010 \\
selective coating & 564 & 0.026
\end{tabular}

the regeneration of both CR-based and BP-based films after exposition to $\mathrm{NO}_{2}$ is poor. On the contrary, regeneration of BP-based films exposed to ammonia is much better.

\section{Conclusions}

This work presents investigations on fabrication technology and characterization of porous silica films which are sensitized to ammonia and nitrogen dioxide. Sensitization was achieved by immobilization of $\mathrm{pH}$-sensitive dyes. Two dyes were used: BP and CR. It was shown that films sensitized with $\mathrm{BP}$ are sensitive to both $\mathrm{NH}_{3}$ and nitrogen $\mathrm{NO}_{2}$, whereas $\mathrm{CR}$ based films are sensitive only to $\mathrm{NO}_{2}$. Absorbance bands induced by a presence of these gases are spectrally separated high enough that a detection of each gas can be performed by LED diodes operating at different wavelength. Two methods of dye impregnation were utilized. It was shown that deposition of a dye solution by means of painting technique causes formation of additional dye film on porous silica film.

\section{Acknowledgments}

This work is funded by Polish Ministry of Science and Higher Education within a scope of the grant N R01 0034 $06 / 2009$ as well as by funding of the Faculty of Electrical Engineering of the Silesian University of Technology within a scope of the Grant BK-257/RE4/2011.

\section{References}

[1] T.J. Montague, A.R. Macneil, Chest 77, 496 (1980).

[2] K. Mukala, J. Pekkanen, P. Tiittanen, S. Alm, R. Salonen, J. Tuomisto, Europ. Respirat. J. 13, 1411 (1999).

[3] K. Wetchakun, T. Samerajai, N. Tamaekong, C. Liewhiran, C. Siriwong, V. Ktuefu, A. Wisitsoraat, A. Tunntranont, S. Phanichphant, Sensors Actuators B 160, 580 (2011).

[4] A. Gomes, E. Fernandes, J.L.F.C. Lima, J. Fluoresc. 16, 119 (2006).

[5] H.S. Mader, O.S. Wolfbeis, Anal. Chem. 82, 5002 (2010).

[6] S.-I. Ohira, E. Wanikasekara, D.M. Rudkevich, P.K. Dasgupta, Talanta 77, 1814 (2009).

[7] Y. Shang, X. Wang, E. Xu, C. Tong, J. Wu, Anal. Chim. Acta 685, 58 (2011).

[8] P. Karasiński, Opt. Appl. 33, 477 (2003).

[9] P. Karasiński, J. Jaglarz, M. Reben, E. Skoczek, J. Mazur, Opt. Mater. 33, 1989 (2011).

[10] P. Karasiński, R. Rogoziński, Opt. Commun. 269, 76 (2007).

[11] C. Tyszkiewicz, P. Karasiński, R. Rogoziński, Acta Phys. Pol. A 118, 1262 (2010).

[12] P. Karasiński, C. Tyszkiewicz, R. Rogozinski, Acta Phys. Pol. A 120, 651 (2011).

[13] P. Karasiński, Opt. Appl. 32, 775 (2002).

[14] P. Karasiński, R. Rogoziński, Opt. Commun. 281, 2472 (2008).

[15] C. Tyszkiewicz, Opt. Appl. 42, 555 (2012).

[16] S.J. Mechery, J.P. Singh, Anal. Chim. Acta 557, 123 (2006).

[17] A.Og. Dikovska, G.B. Atanasova, N.N. Nedyalkov, P.K. Stefanov, P.A. Atanasov, E.I. Karakoleva, A.Ts. Andreev, Sensors Actuators B 146, 331 (2010).

[18] Z. Qi, K. Itoh, M. Murabayashi, H. Yanagi, J. Lightwave Technol. 18, 1106 (2000).

[19] R. Rogoziński, Opto-Electron. Rev. 13, 229 (2005).

[20] P. Karasiński, Opto-Electron. Rev. 15, 168 (2007).

[21] P. Karasiński, C. Tyszkiewicz, R. Rogoziński, Acta Phys. Pol. A 118, 1168 (2010).

[22] P. Karasiński, C. Tyszkiewicz, R. Rogoziński, J. Jaglarz, J. Mazur, Thin Solid Films 519, 5544 (2011).

[23] P. Karasiński, Opto-Electron. Rev. 19, 10 (2011).

[24] P. Karasiński, P., C. Tyszkiewicz, R. Rogoziński, Opt. Appl. 41, 351 (2011). 